\title{
Where advocacy meets patient-centered care-cost considerations in breast reconstruction decision-making
}

\author{
Whitney Lane ${ }^{1}$, Brett T. Phillips ${ }^{1}$, Anaeze C. Offodile II $^{2,3,4}$ \\ ${ }^{1}$ Division of Plastic Surgery, Duke University Medical Center, Durham, NC, USA; ${ }^{2}$ Department of Plastic Surgery, ${ }^{3}$ Department of Health Services \\ Research, MD Anderson Cancer Center, Houston, TX, USA; ${ }^{4}$ The Baker Institute for Public Policy, Rice University, Houston, TX, USA \\ Contributions: (I) Conception and design: All authors; (II) Administrative support: AC Offodile 2nd; (III) Provision of study materials or patients: \\ None; (IV) Collection and assembly of data: W Lane, (V) Data analysis and interpretation: None; (VI) Manuscript writing: All authors; (VII) Final \\ approval of manuscript: All authors. \\ Correspondence to: Anaeze C. Offodile II, MD, MPH. Department of Plastic Surgery, MD Anderson Cancer Center, 1515 Holcombe Boulevard, \\ Houston, TX 77030, USA. Email: acoffodile@mdanderson.org.
}

\begin{abstract}
Cancer care in the United States is unquestionably expensive. In 2017, annual costs related to cancer-related treatment reached $\$ 180$ billion. There is clear evidence that the increased cost of cancer care translates to financial hardship. This hardship is widespread, impacting as many as $75 \%$ of patients and their families with associated adverse sequelae. Growing recognition of the negative impact of cancer-related treatment costs on patients and their families led to the creation of the term "financial toxicity". The present editorial is borne out of the need to bring this problem to the attention of practicing surgeons, as to the best of our knowledge is still underreported in our specialties.
\end{abstract}

Keywords: Financial toxicity; breast reconstruction (BR); cost

Submitted Jan 10, 2020. Accepted for publication Mar 06, 2020.

doi: $10.21037 /$ gs.2020.03.21

View this article at: http://dx.doi.org/10.21037/gs.2020.03.21

\section{Introduction}

Cancer care in the United States is unquestionably expensive. In 2017, annual costs related to cancer-related treatment reached $\$ 180$ billion (1). Advances in treatments and diagnostics such as targeted therapies and oncotype sequencing have to a large extent lead to this trajectory. The insurance marketplace has responded by shifting increasing portions of cancer treatment costs onto patients in the form of rising deductibles ("high deductible health plans") and a dependence on cost-sharing insurance design (i.e., premiums, co-payments, and co-insurance) (2). Currently, average out-of-pocket expenditures for cancer patients approach $\$ 5,000$ per year and $25 \%$ of cancer patients now report using all or most of their savings to pay for their cancer care (3). Even among insured patients, healthcare expenses can be unaffordable (4). A recent review of a nationally representative sample of American households, noted that only $45-50 \%$ had finances immediately available to pay a median-to-high health care deductible (5).

There is clear evidence that the increased cost of cancer care translates to financial hardship. This hardship is widespread, impacting as many as $75 \%$ of patients and their families (6) with associated adverse sequelae. Examples include income interruption, poor health quality-of-life, treatment non-adherence, poor physical and mental wellbeing, and disconcertingly early death among cancer survivors (6). Growing recognition of the negative impact of cancer-related treatment costs on patients and their families led to the creation of the term "financial toxicity". The present editorial is borne out of the need to bring this problem to the attention of practicing surgeons, as to the best of our knowledge is still underreported in our specialties.

\section{Financial toxicity}

Conceptually, financial toxicity can be broken down into 
objective costs and the subjective experience of hardship. Objective costs include direct costs (e.g., medical bills from hospital visits, clinic visits, medications, imaging) and indirect costs (e.g., travel expenses, lost wages, and caregiving). Although some patients may be able to afford the objective costs of cancer care, they may still experience financial toxicity driven by unplanned lifestyle changes, depletion of savings, and concerns over future financial health (7).

The financial distress related to the high direct costsof-care is exacerbated by the time off from work or lost productivity due to cancer therapies. This creates a vicious cycle or deleterious feedback loop. Individuals with cancer were noted to be at four-fold greater risk of work absenteeism relative to matched controls (8). Further, more aggressive treatment, including chemotherapy and invasive surgery, has been associated with a significant risk of disrupted employment (9).

\section{Financial hardship in the context of breast cancer and the role of cost conversations}

In light of its policy salience and a prevalence of risk factors for financial toxicity (i.e., gender, younger age at time of diagnosis, and existing racial disparities) breast cancer has become the archetypal condition for much of the public discussion around high treatment costs (10). Nationally, breast cancer treatment costs are estimated to reach $\$ 20$ billion by 2020 (8) and these patients experience a substantial portion of this financial burden. It has been reported that between $30-50 \%$ of women are at least somewhat worried about their finances due to breast cancer treatment (11). In a recent national survey of female breast cancer patients, that reflected a well-insured population, $43 \%$ of respondents considered cost when making treatment decisions (4). Of note, progressively more women prioritized costs in their surgical decision-making process as respective annual income fell. In the hierarchy of preferences for women with a household income $<45,000 /$ year, costs of care surpassed loss of sensation, breast preservation, breast appearance, avoidance of radiation and need for long term surveillance (4). Furthermore, although there was wide variation by insurance status and treatment modality in out of pocket costs, $50 \%$ of breast cancer patients report objective financial burden related directly to the cost of their care $(4,11)$. In fact, women undergoing treatment for breast cancer reported cutting down on spending including utilities and food directly as a result of their cancer treatment and up to $15 \%$ of women reported significant loss of wages due to time away from work (11).

\section{Patient centered interventions to reduce financial toxicity}

For decades hospitals have utilized financial counselors to assist patients in getting access to charity care or signing up for Medicaid. However, these resources are often not readily available at the time of the initial clinic encounter and have limited utility for the majority of cancer patients with insurance. Furthermore, patients rarely see financial counselors pre-emptively to avoid financial harm. More often than not, this occurs, after the determination that there is an inability to cover the costs of care (12). Newer models of financial navigators specific to oncology have been promising (12). These programs have been shown to reduce rates of financial toxicity by proactively guiding patients through available health insurance options, optimizing their coverage, and informing patients about implications of treatment plans on cost.

Regardless of the type of financial support available at each healthcare institution, patients at risk for financial harm need to be identified early in their care continuum. This best ensures the effective implementation of any proactive steps to mitigate financial toxicity. Therefore, all members of the care team including plastic surgeons, should discuss the costs associated with their treatment recommendations openly and honestly with patients. In fact, in 2009, the American Society of Clinical Oncology recommended that oncologists discuss the costs of care with patients prior to treatment (13). More recently, the Institute of Medicine proposed that patient-provider shared decision-making models that include cost be considered as metrics for quality cancer care (14). Empirical evidence exists for the association between cost discussions with care providers and an increased likelihood for the following: a referral to financial assistance, utilization of less expensive medications, and decreased frequency of lab tests (15). These cost-conscious measures can dampen the incidence and severity of financial toxicity.

\section{Breast reconstruction (BR), preference- sensitivity and cost discussions}

Long-term clinical trial data and modern observational studies have consistently shown that the surgical options for early-stage breast cancer (lumpectomy with radiation 
$v s$. mastectomy) are equally effective with respect to longterm survival (16). Thus, decisions for breast cancer surgery treatment are highly preference-sensitive. Women consider many factors when weighing each surgical choice, including their desire for breast preservation, options for reconstruction, aesthetic results, expected surveillance, risk of recurrence, and peace of mind (17). Furthermore, up to $60 \%$ of women who choose to undergo mastectomy opt for BR (18). Although BR has been shown to improve overall satisfaction and quality of life (19), there has been no demonstrated survival benefit. Thus, choices surrounding BR are also highly preference sensitive including both the timing and type of reconstruction. Decisions regarding autologous $v s$. implant-based reconstruction are largely driven by aesthetic result, time to recovery, scarring in other parts of the body, avoidance of foreign material, and risk of complications (20). Lack of awareness may contribute to plastic surgeons not routinely considering how these decisions may ultimately impact costs of care. Notably, the various BR subtypes vary widely in both overall costs and complication profile. The latter is relevant because it represents an unplanned and often protracted treatment expense.

There is currently a dearth of information on financial distress directly attributable to BR. BR patients are generally financially better off, more likely to be married and have higher rates of private insurance relative to patients who do not undergo reconstruction (21). However, women undergoing BR are also likely to undergo more than one operative intervention, with reported average of 2.4 surgeries per patient (22). And 1 in 10 women undergo more than 3 major operative procedures directly related to BR (22). This increases the risk of complications and need to take time off from work. In fact, one study found that patients undergoing bilateral mastectomy with reconstruction were at highest risk of taking $>1$ month off of work or stopping work all together (9). Therefore, although the BR population may be better off financially prior to their diagnosis, hardship related to BR is likely to look different in this population. Thus, qualitative research is much needed in this area to determine (I) what types of financial hardship do patients typically experience related to BR, (II) patient perspectives on cost conversations as they relate to BR, and (III) the optimal timing of these conversations. Further it remains unclear if cost conversations in this patient population will ultimately translate into reduced financial strain for patients and alter BR decision-making.

\section{Cost conversations and shared decision-making}

Plastic surgeons are already accustomed to effectively navigating preference-sensitive topics in both reconstructive and cosmetic practice. However, the literature demonstrates that only $30 \%$ of physicians treating cancer patients include cost transparency as part of their routine clinical practice (23). One study found that one-third of women considered costs when making surgical decisions for breast cancer, yet the overwhelming majority (78\%), never discussed costs with their medical team despite their reported desire for transparency (4). If the goal of a shared decision-making process is to maximize the likelihood of preference-concordant care, then more cost-conversations are inarguably called for. Unfortunately, many providers report discomfort with cost conversations as a major barrier to effective inclusion of cost into shared decision making for cancer (23). Because the implications for clinical practice are significant, this presents a strong case for increased administrative support (i.e., financial navigators, patient assistance programs) and provider training on financial distress assessment. Plastic surgeons as part of the multidisciplinary cancer care team, should incorporate cost of care discussions, and to the extent possible, financial toxicity assessment as part of their clinical practice. Lastly, protecting patient welfare (physical, emotional) is one of the central tenets of medical professionalism and ethical practice (24). Ensuring that BR does not engender financial harm, via meaningful cost conversations, is deeply aligned with this.

\section{Conclusions}

Financial hardship is an increasingly recognized problem among breast cancer patients that is still poorly characterized within the context of BR. Although this article is not an exhaustive systematic review, we attempted to present a summary of existing knowledge and make a case for the incorporation of financial hardship risk assessment in contemporary BR. Rigorous scholarship is clearly needed to unpack (I) the relationship between financial hardship and BRs outcomes and (II) suggest appropriate interventions. Notwithstanding, we posit that the time to have cost conversations become a part of evidence-based $\mathrm{BR}$ practice is already upon us.

\section{Acknowledgments}

Financial support was generously provided by the University 
Cancer Foundation grant via the Sister Institution Network Fund (SINF) at the University of Texas MD Anderson Cancer Center.

\section{Footnote}

Provenance and Peer Review: This article was commissioned by the Guest Editors (Charles E. Butler, Carrie Chu, and Margaret Roubaud) for the series "New Frontiers in Breast Reconstruction" published in Gland Surgery. The article was sent for external peer review organized by the Guest Editors and the editorial office.

Conflicts of Interest: All authors have completed the ICMJE uniform disclosure form (available at http://dx.doi. org/10.21037/gs.2020.03.21). The authors have no conflicts of interest to declare.

Ethical Statement: The authors are accountable for all aspects of the work in ensuring that questions related to the accuracy or integrity of any part of the work are appropriately investigated and resolved.

Open Access Statement: This is an Open Access article distributed in accordance with the Creative Commons Attribution-NonCommercial-NoDerivs 4.0 International License (CC BY-NC-ND 4.0), which permits the noncommercial replication and distribution of the article with the strict proviso that no changes or edits are made and the original work is properly cited (including links to both the formal publication through the relevant DOI and the license). See: https://creativecommons.org/licenses/by-nc-nd/4.0/.

\section{References}

1. Himmelstein DU, Woolhandler S, Almberg M, et al. The U.S. Health Care Crisis Continues: A Data Snapshot. Int J Health Serv 2018;48:28-41.

2. Yabroff KR, Lund J, Kepka D, et al. Economic burden of cancer in the United States: estimates, projections, and future research. Cancer Epidemiol Biomarkers Prev 2011;20:2006-14.

3. Bernard DS, Farr SL, Fang Z. National estimates of out-of-pocket health care expenditure burdens among nonelderly adults with cancer: 2001 to 2008. J Clin Oncol 2011;29:2821-6.

4. Greenup RA, Rushing C, Fish L, et al. Financial Costs and Burden Related to Decisions for Breast Cancer Surgery. J
Oncol Pract 2019;15:e666-76.

5. Ramsey SD, Bansal A, Fedorenko CR, et al. Financial Insolvency as a Risk Factor for Early Mortality Among Patients With Cancer. J Clin Oncol 2016;34:980-6.

6. Zafar SY, Abernethy AP. Financial toxicity, Part I: a new name for a growing problem. Oncology (Williston Park) 2013;27:80-1, 149.

7. Thomas T, Hughes T, Mady L, et al. Financial Toxicity: A Review of the Literature and Nursing Opportunities. Clin J Oncol Nurs 2019;23:5-13.

8. Chang S, Long SR, Kutikova L, et al. Estimating the cost of cancer: results on the basis of claims data analyses for cancer patients diagnosed with seven types of cancer during 1999 to 2000. J Clin Oncol 2004;22:3524-30.

9. Jagsi R, Abrahamse PH, Lee KL, et al. Treatment decisions and employment of breast cancer patients: Results of a population-based survey. Cancer 2017;123:4791-9.

10. Lentz R, Benson AB 3rd, Kircher S. Financial toxicity in cancer care: Prevalence, causes, consequences, and reduction strategies. J Surg Oncol 2019;120:85-92.

11. Jagsi R, Ward KC, Abrahamse PH, et al. Unmet need for clinician engagement regarding financial toxicity after diagnosis of breast cancer. Cancer 2018;124:3668-76.

12. Sherman D, Fessele KL. Financial Support Models: A Case for Use of Financial Navigators in the Oncology Setting. Clin J Oncol Nurs 2019;23:14-8.

13. Meropol NJ, Schrag D, Smith TJ, et al. American Society of Clinical Oncology Guidance Statement: The Cost of Cancer Care. J Clin Oncol 2009;27:3868-74.

14. Committee on Improving the Quality of Cancer Care: Addressing the Challenges of an Aging Population, Board on Health Care Services, Institute of Medicine. In: Levit L, Balogh E, Nass S, et al. editors. Delivering High-Quality Cancer Care: Charting a New Course for a System in Crisis. Washington (DC): National Academies Press (US). Copyright 2013 by the National Academy of Sciences. All rights reserved; 2013.

15. Shih YT, Nasso SF, Zafar SY. Price Transparency for Whom? In Search of Out-of-Pocket Cost Estimates to Facilitate Cost Communication in Cancer Care. Pharmacoeconomics 2018;36:259-61.

16. Hwang ES, Lichtensztajn DY, Gomez SL, et al. Survival after lumpectomy and mastectomy for early stage invasive breast cancer: the effect of age and hormone receptor status. Cancer 2013;119:1402-11.

17. Lee CN, Chang Y, Adimorah N, et al. Decision Making about Surgery for Early-Stage Breast Cancer. J Am Coll Surg 2012;214:1-10. 
18. Jagsi R, Jiang J, Momoh AO, et al. Trends and variation in use of breast reconstruction in patients with breast cancer undergoing mastectomy in the United States. J Clin Oncol 2014;32:919-26.

19. Pusic AL, Matros E, Fine N, et al. Patient-Reported Outcomes 1 Year After Immediate Breast Reconstruction: Results of the Mastectomy Reconstruction Outcomes Consortium Study. J Clin Oncol 2017;35:2499-506.

20. Politi MC, Lee CN, Philpott-Streiff SE, et al. A Randomized Controlled Trial Evaluating the BREASTChoice Tool for Personalized Decision Support About Breast Reconstruction After Mastectomy. Ann Surg 2020;271:230-7.

21. Sergesketter AR, Thomas SM, Lane WO, et al. The Influence of Marital Status on Contemporary Patterns of

Cite this article as: Lane W, Phillips BT, Offodile AC 2nd. Where advocacy meets patient-centered care-cost considerations in breast reconstruction decision-making. Gland Surg 2021;10(1):507-511. doi: 10.21037/gs.2020.03.21
Postmastectomy Breast Reconstruction. J Plast Reconstr Aesthet Surg 2019;72:795-804.

22. Roberts A, Baxter N, Camacho X, et al. Once is Rarely Enough: A Population-Based Study of Reoperations after Postmastectomy Breast Reconstruction. Ann Surg Oncol 2015;22:3302-7.

23. Greenup RA, Rushing CN, Fish LJ, et al. Perspectives on the Costs of Cancer Care: A Survey of the American Society of Breast Surgeons. Ann Surg Oncol. 2019;26:3141-51.

24. ABIM Foundation. American Board of Internal Medicine; ACP-ASIM Foundation. American College of PhysiciansAmerican Society of Internal Medicine; European Federation of Internal Medicine. Medical professionalism in the new millennium: a physician charter. Ann Intern Med 2002;136:243-6. 